\title{
500 ANOS DE ASSISTÊNCIA JUDICIÁRIA NO BRASIL
}

\author{
Arthur Bragança de Vasconcellos Weintraub \\ Mestrando pelo Departamento de Direito do Trabalho da \\ Faculdade de Direito da Universidade de São Paúlo
}

Resumo:

$\mathrm{O}$ assunto diz respeito à assistência judiciária no Brasil, desde 0 seu descobrimento até os dias atuais, numa abordagem jurídica e histórica.

Abstract:

The subject is about legal aid in Brazil, since its discovery until today, in a historical and legal approach.

Unitermos: assistência judiciária; contexto histórico-jurídico brasileiro.

De 1580 a 1640, Portugal e Espanha tiveram um mesmo rei, Felipe II. Camões explica bem essa transição, pois ao morrer em 1580 disse 'não me contentei em morrer pela minha Pátria, mas com ela" Assim o embasamento jurídico da assistência judiciária no Brasil teve origem nas Ordenações Filipinas, as quais vieram a substituir as Ordenações Manuelinas em 1603. Como o rei Felipe II era filho de mãe portuguesa (o pai era espanhol), a primeira língua que lhe foi ensinada foi o português. Logo, o rei teve certa complacência em relação à elaboração do ordenamento jurídico de Portugal. Mas certas questões não-regionais que constavam das Ordenações tiveram de ser vinculadas ao ordenamento português.

No Brasil, as Ordenações Filipinas vigoraram até 1917 (entrada em vigor do Código Civil, de Clóvis Beviláqua, apesar de que em numerosos artigos do Código há a influência direta dessas Ordenações). Sobre a assistência judiciária, o Livro III, Título 84, $§ 10$, da Lei de 1823 (embasada nas Ordenações Filipinas) especifica:

1. Trabalho feito como bolsista da FAPESP (iniciação científica). 
"Em sendo o agggravante tão pobre que jure não ter bens móveis, nem de raiz, nem por onde pagua o aggravo, e dizendo na audiência uma vez $o$ Pater Noster pela alma del Rey Don Diniz, ser-Ihe-á havido, como que pagasse os novecentos réis, contanto que tire de tudo certidão dentro do tempo, em que havia de pagar o aggravo.

Oriundo das Ordenações Filipinas, o princípio da gratuidade dos serviços advocatícios, nas causas civeis e criminais, veio a garantir a igualdade de condições dos pobres em juízo.

Contudo, esse amparo legal aos necessitados não era de cunho processual, ou seja, como pressuposto de um devido processo legal. A assistência estava pautada em princípios cristãos de caridade.

Fato marcante em nossa História consistiu na nomeação, em 1871, pela Alçada Régia, do dr. José de Oliveria Fagundes, advogado da Santa Casa de Misericórdia do Rio de Janeiro, para a defesa dos 29 inconfidentes, entre eles Joaquim José da Silva Xavier, o alferes Tiradentes. Isso frente à impossibilidade da constituição de defensor, mesmo pelos inconfidentes com posses.

O instituto da Ordem dos Advogados Brasileiros, em 1870, veio a instituir a assistência judiciária, assim como a Câmara Municipal da Corte (18801884). Foi finalmente sancionada pelo Código Civil, de 1917, e assim implementada nos Estados mais importantes, dentro dos Estatutos Processuais Estaduais.

Com o advento da Constituição Federal, de 1934, a assistência judiciária foi recepcionada pelo texto constitucional no art. 113, n. 32, no contexto dos Direitos e Garantias Individuais. Dizia o referido artigo:

" A União e os Estados concederão aos necessitados assistência judiciária, criando, para esse efeito, órgãos especiais e assegurando a isenção de emolumentos, custas, taxas e selos."

Nesse caso, o legislador constituinte teve a preocupação com a efetividade da assistência como forma de obtenção de Justiça e isonomia, mediante a previsão da criação de órgãos especiais. Uma das funções do Estado era constitucionalmente prevista como assistência judiciária, isso até o advento da Constituição Federal de 1937, quando a assistência não foi recepcionada pelo texto constitucional. 
Em 1946, segundo o contexto social-democrata vigente na época, a assistência judiciária foi novamente recepcionada pela Constituição brasileira, mais precisamente no art. 141, que dizia:

A Constituição assegura aos brasileiros e aos estrangeiros residentes no país a inviolabilidade dos direitos concernentes à vida, à liberdade, à segurança individual e à propriedade nos termos seguintes.

$\S 35$ O poder público, na forma que a lei estabelecer, concederá assistência judiciária aos necessitados."

Como vimos, trata-se o parágrafo citado de uma norma de eficácia contida, já que foi necessária a elaboração da Lei n. 1.060/50, que veio a estabelecer "normas para a concessão de assistência judiciária aos necessitados."

No âmbito dos Direitos e Garantias Individuais da Constituição, de 1967, no art. 150, § 32, foi abordada a assistência judiciária, assim como na Emenda Constitucional n. 1 , de 1969 , que na realidade consistiu numa Constituição outorgada, no art. $153, \S 32$, que especificava:

“ será concedida assistência judiciária aos necessitados, na forma da Iei."

Finalmente, na Constituição de 1988 (no que diz respeito à competência legislativa concorrente entre União, Estados e Distrito Federal, no art. 24, inciso XIII, são inclusas como matérias legislativas a assistência jurídica e a defensoria pública), art. $5^{\circ}$ inciso LXXIV. houve uma previsão mais ampla englobando a assistência judiciária:

- Estado prestará assistência jurídica integral e gratuita aos que comprovarem insuficiência de recursos".

A Lei n. 1.060, de 05.02.1950, não é a primeira lei brasileira a respeito da assistência judiciária aos necessitados; haja vista que o Código de Processo Civil, de 1939, já abordava essa forma de amparo estatal (grande parte dos artigos relacionados à assistência judiciária foram repassados para a Lei n. 1.060/50). Uma 
das características da Lei n. 1.060/50, promulgada na vigência do Código de 1939, é formatação um tanto quanto emendada.

Sendo exceção ao princípio de que cabe à parte sucumbente arcar com honorários e custas processuais, vigente atualmente, essa não era a regra à época de 1939 ou 1950, onde, em alguns casos, outrossim especificados em lei (como no caso em que ação decorresse de culpa ou dolo da parte, ou mesmo nos casos de extinção da ação sem o julgamento do mérito, conhecido como absolvição de instância pelo Código de 1939), a condenação da sucumbência não era a regra.

Em 1964 foi emendado o Código de 1939 e a sucumbência passou a ser generalizada. Em 1973, com o Código de Processo Civil atual, esse ônus da sucumbência permaneceu regra. A especificação da Lei n. 1.060 no sentido de limitar os honorários advocatícios em $15 \%$, dessa forma, não constitui arbitrariedade com o escopo de fixar um patamar inferior de renda ao advogado do beneficiário da assistência judiciária, que seria de 10 a $20 \%$ do valor da causa, pois em 1950 não havia generalização, tampouco parâmetros.

Segundo o art. $2^{\circ}$ da Lei de Assistência Judiciária:

"Gozarão dos benefícios desta lei os nacionais ou estrangeiros residentes no país, que necessitem recorrer à Justiça penal, civil, militar ou do trabalho" (grifo nosso)

E, de acordo com o parágrafo único:

"Considera-se necessitado, para os fins legais, todo aquele cuja situação econômica não lhe permita pagar as custas do processo e os honorários de advogado, sem prejuizo do sustento próprio ou da família" (grifos nossos)

Antes era necessária uma prova de que o beneficiário fosse realmente pobre, mediante atestado de pobreza. Hoje basta uma simples declaração, segundo simplificações oriundas de emendas a artigos da lei relacionadas à requisição de gratuidade. A Constituição Federal, de 1988, previu um conceito novo em conta dessa questão ao prever a prestação da assistência jurídica integral e gratuita aos que comprovarem insuficiência de recursos.

Seria concedida pelo juiz a gratuidade processual, no âmbito da Justiça gratuita, e a isenção de despesas. O termo constitucional é mais amplo do 
que o conceito da assistência judiciária contido na Constituição Federal, de 1969. O conceito de assistência jurídica da Constituição, de 1988, englobaria, inclusive, a consultoria e a atividade juridica extrajudicial (a assistência abrange a fase préprocessual).

O beneficiário assistido está, por exemplo, isento do pagamento de qualquer perícia, independentemente de quem a tenha realizado, pois não haveria distinção "entre peritos das partes e perito judicial, pois sua nomeação pelo Juízo torna tal atividade munus público a que o profissional liberal está sujeito" (JTJ 143/177).

Com relação ao benefício dado a estrangeiros residentes no País, há tratados específicos com alguns países, firmados por meio de acordos de reciprocidade, na prestação de assistência judiciária. Nesses países, mediante 0 tratado, há o direito assistencial equiparando-se o brasileiro ao nacional (desde que no Brasil se faça o mesmo). São Estados que firmaram tratados com o Brasil nesse sentido: Argentina (D. 62978/68); Bélgica (D. 41908/57); França (D. 91207/85); Holanda (D. 53923/64). As designações em diversos países, em relação à assistência judiciária incorporada às legislações peculiares, variam quanto à definição, mas 0 escopo continua sendo sempre muito análogo, devido à influência histórica (Armenrecht, Assistance Judiciaire, Legal Aid, Defensa de Pobre).

Logo, o conceito de assistência judiciária consiste num auxílio (serviço jurídico prestado aos pobres gratuitamente) prestado em juízo perante o Judiciário. Assistência juridica englobaria todo serviço jurídico prestado por advogado. Assim, não seria somente uma mera gratuidade processual que é garantida por lei, mas também uma assistência técnica prevista na Constituição Federal. Os benefícios da assistência judiciária englobam todos os atos processuais, em todas as instâncias (art. $9^{\circ}$ da Lei de Assistência Judiciária).

Segundo 0 art. $4^{\circ}$ da Lei n. 7.510/86 (que veio complementar a Lei $n$. 1.060/50), basta a afirmação na petição inicial em referência à falta de condições. $\mathrm{O}$ juiz teria 72 horas para indeferir ou deferir o pedido "prima facie"

Diz o $§ 1^{\circ}$ desse artigo:

"Presume-se pobre, até prova em contrário, quem afirmar essa condição nos termos desta lei, sob pena de pagamento até o décuplo das custas judiciais" 
Esse dispositivo tende a evitar a utilização desse benefício de maneira errônea ou maliciosa, segundo um critério de sanção meramente econômica, mesmo tendo havido um incidente de falsidade declaratória. Caso não haja estipulação em contrário, a decisão concedente do benefício tem eficácia ex tunc, retroagindo à data da propositura da ação.

E, segundo o $\S 2^{\circ}$ do mesmo artigo:

A impugnação do direito à assistência judiciária não suspende o curso do processo e será feita em autos apartados"

Ora, essa não, suspensividade é essencial à manutenção do escopo do benefício, já que a suspensão do benefício poderia acarretar o óbice total da parte beneficiada em prosseguir no processo.

Há uma Ementa do Superior Tribunal de Justiça no seguinte sentido: Para que a parte obtenha o benefício da assistência judiciária, basta a simples afirmação de sua pobreza, até prova em contrário" (STJ, $3^{\mathrm{a}}$ T. R. Esp. 1009-SP, j. 24.10.89, rel. min. Nilson Naves in RSTJ 07/414, março/90). Segundo Pontes de Miranda, caso o juiz da causa negue o benefício ao necessitado, haverá uma "infração de direito líquido e certo" (não-dependendo de prova o estado de necessidade), podendo-se ingressar em Juízo com mandado de segurança.

O art. 12 da Lei n. 1.060/50 prevê:

A parte beneficiada pela isenção de pagamento de custas ficará obrigada a pagá-las, desde que possa fazê-lo sem prejuizo do sustento próprio ou da família. Se dentro de 5 (cinco) anos, a contar da sentença final, o assistido não puder satisfazer tal pagamento, a obrigação ficará prescrita"

Essa previsão não foi recepcionada pela Constituição Federal, de 1988. Isso porque a Constituição Federal, de 1988, em seu art. $5^{\circ}$ inciso LXXIV. diferentemente da Constituição Federal, de 1969, art. 153, § 32, não se reporta à lei infraconstitucional (STJ, relator ministro Adhemar Maciel, RT 729/159). Mas há jurisprudência contrária à do STJ (LEX 37/94-95, RJTJSP 125/262, RT 688/130, JTJ 170/181). 
Cotejando-se o parágrafo único do art. 263 do Código de Processo Penal, que diz:

"O acusado, que não for pobre, será obrigado a pagar os honorários do defensor dativo, arbitrados pelo juiz"

Assim, segundo esse aspecto, da mesma forma que um réu revel amparado pelo benefício da assistência judiciária deve pagar pelo serviço a ele prestado caso tenha condições, no ínterim de cinco anos, o beneficiado deveria arcar com as despesas públicas despendidas, caso sua situação econômica permitisse (pois haveria um desvirtuamento do benefício se pessoas, com condições para constituir advogado ou defensor, fossem assistidas por defensor público, ou mesmo reembolsar os gastos públicos, caso situação posterior de até cinco anos permitisse).

Contudo, quando a Constituição vem a garantir esse tipo de assistência, não significa que necessariamente caberá ao Estado verificar a comprovação da insuficiência de recursos, podendo ter um crivo mais flexível nesse aspecto. A Constituição Estadual de São Paulo utiliza a expressão "aos que declararem insuficiência de recursos"

Foi no Estado de São Paulo, inclusive, em 1935, onde se formulou o primeiro serviço estatal de assistência judiciária do Brasil, com a remuneração de advogados que exerciam esse múnus público. A Constituição Federal, de 1937. não acolheu o tratamento constitucional dado à assistência judiciária, retornando somente ao texto constitucional em 1946, num contexto social mais ligado à democracia e aos direitos individuais.

É preciso ressaltar que aquilo que aparenta ser uma quantia irrisória, tal como o preço de uma cópia autenticada, pode vir a ser um ônus insuportável à determinadas pessoas pobres. E, ainda, o fato da pessoa possuir algum bem (como, por exemplo: uma linha telefônica, um automóvel ou mesmo uma casa própria), não afasta sua situação de hipossuficiência de recursos, tendo aquele que presta a assistência jurídica que verificar caso a caso, assim como caberá ao juiz, que conhecendo a lei (iura novit curia) concederá gratuidade processual, envolvendo todas as isenções necessárias. Isso porque não seria plausível que essa pessoa devesse vender seu bem (como casa, carro ou telefone, amealhados ao longo da vida) para custear os encargos processuais. Aquilo que realmente deve ser aferido consistiria na renda fixa e gastos gerais; se há prejuízo real do sustento do indivíduo. 
Há, inclusive, acórdão (RT 686/185) tratando do assunto da atividade ou cargo exercido pelo interessado, ligado então aos emolumentos, pelo interessado no benefício; deve haver uma impugnação à essa miserabilidade alegada, em relação à presunção de tratar-se de pessoa pobre (tendo em vista que acaso a parte contrária não-impugne o pedido de assistência jurídica, fatalmente a concessão do benefício será aprovada pelo magistrado). E na RT 678/88, que trata da questão do proprietário de poucos bens, que mesmo tendo posses, ainda assim pode ser sujeito dos benefícios assistenciais.

Entretanto, mesmo em relação à declaração de insuficiência de recursos, cabe não-só ao juiz analisar a concessão do benefício, como poderá a parte contrária impugnar essa concessão. Um sujeito que, por exemplo, não possui bens em seu nome; mas possui uma renda mensal vultosa, não poderá vir a ser beneficiário dessa gratuidade.

Inobstante, no caso de uma viúva que possua dois ou três imóveis, garantindo seu sustento, não poderá ser taxada de abastada e insuscetível de ser beneficiária da assistência judiciária gratuita e integral. $\mathrm{O}$ patrimônio deveria ser tão-somente um sinal evidente e indubitável de riqueza. Negando o magistrado a gratuidade nesse caso, caberia normalmente recurso. Um critério objetivo não solucionaria a questão, mesmo porque se fundamentando em nove salários mínimos, por exemplo, poderia ainda haver pessoas sem gasto algum, como um estudante de renda mensal de nove salários mínimos que estaria objetivamente sujeito ao benefício, mas no caso concreto seria descabido.

Bibliografia

BANDEIRA DE MELLO, Celso Antônio. O conteúdo jurídico do princípio da igualdade. São Paulo, Editora R.T., 1989.

BOBBIO, Norberto; em conjunto com Nicola Matteucci e Gianfranco Pasquino. Dicionário de Política. $5^{a}$ ed., Brasília, Editora da Universidade de Brasília, 1993.

CANOTILHO, José Joaquim Gomes. Direito Constitucional, Coimbra, Ed. Almedina, 1991.

CAPPELlETTI, Mauro (cooperação de Bryant Garth). Acesso à Justiça. Porto Alegre, Sergio Antonio Fabris Editor, 1988. Tradução de Ellen Gracie Northfleet. 
FERENCZY, Peter Andreas. Considerações sobre aspectos da evolução da defensoria pública, diante da legislação, da jurisprudência e da doutrina, desde a CF de 1988 até 6/1993. São Paulo, R.T., 84(722):75-83, dez., 1995.

LEAL JUNIOR, Cândido Alfredo Silva. A comprovação da insuficiência de recursos para concessão da assistência jurídica gratuita, $R$. de Processo, São Paulo, 16(62):268-77. abr/jun., 1991.

MORAES, Humberto Penã de. Assistência Judiciária Pública e os mecanismos de acesso à Justiça no Estado Democrático. In: Participação e processo. São Paulo, Ed. R.T., 1988.

PINHEIRO, Eduardo Bezerra. Breves observações acerca da Lei n. 1.060/50. São Paulo, R.T., 85(733) 94-108, nov., 1996.

PINTO, Robson Flores. A garantia constitucional de assistência jurídica estatal aos hipossuficientes. Cadernos de Direito Constitucional e Ciências Politicas, São Paulo, 1(3):101-19,abr/jun., 1993.

TUCCI, Rogério Lauria. Direitos e Garantias Individuais no Processo Penal Brasileiro. São Paulo, Ed. Saraiva, 1993. 